\title{
Long-term Variation in the Catch of Major Small Pelagic Fishes Related to Winter Warming in the South Sea, Korea
}

\author{
Seung-Jong Lee ${ }^{*}$ and You-Bong Go ${ }^{1}$ \\ Marine and Environmental Research Institute, Cheju National University, \\ Bukjeju-gun, Jeju-do 695-814, Korea \\ ${ }^{1}$ Division of Applied Marine Science, Cheju National University, \\ Jeju-do 690-756, Korea
}

\begin{abstract}
The relationships among long-term climatic change in the southern part of the Korean peninsula, oceanic conditions of the South Sea, Korea, and winter catches of major small pelagic fishes were analyzed using 33 years of time-series data from 1971-2003. In the early 1990s, winter climatic conditions in the southern part of the Korean peninsula shifted to a warmer regime with higher air temperature, weaker wind speed, and lower relative humidity. Also, winter sea surface temperature (SST) became consistently higher in the South Sea. The annual catch of major small pelagic fishes in the South Sea increased dramatically in the mid 1990s, whereas the catch of total fishes decreased in the late 1980s. In particular, the winter catch started to increase markedly in the late $1980 \mathrm{~s}$, and has remained over $120,000 \mathrm{M} / \mathrm{T}$ since the late $1990 \mathrm{~s}$. Correlation analysis of the winter catch of major small pelagic fishes and environmental factors showed that catch was correlated with air temperature $(r=0.468, P<0.01)$, wind speed $(r=-0.732, P<0.01)$, relative humidity $(r=-0.731, P<0.01)$, and SST $(r=0.672, P<0.01)$. Multiple regression analysis between the winter catch of major small pelagic fishes $(Y)$ and environmental factors $(X)$ resulted in the equation: $Y=-0.017-0.217 X_{3}-0.486 X_{4}+0.325 X_{5}\left(R^{2}=0.754, P<0.000\right)$.
\end{abstract}

Key words: Small pelagic fish, South Sea, Climatic conditions, Oceanic conditions, Winter, Warm regime

\section{Introduction}

Unlike the East and Yellow Seas, the South Sea of Korea has physical, chemical, and biological characteristics that are seasonal, resulting in a high diversity of fisheries resources. In Korea about $70 \%$ of the total fishe-ries species inhabit the South Sea of Korea. The fish catch in the South Sea comprised more than $70 \%$ of the total from coastal and offshore fisheries in the $1980 \mathrm{~s}$, and $80 \%$ in the $1990 \mathrm{~s}$. Therefore, the South Sea of Korea contributes significantly to the Korean fisheries industry (Kim and Kang, 2000; Kim, 2003; Lee, 2004).

Small pelagic fishes such as anchovy (Engraulis japonicus), common mackerel (Scomber japonicus), and horse mackerel (Trachurus japonicus) occur widely in oceans around the world. According to the Food and Agricultural Organization of the United Nations (FAO), small pelagic fishes amounted to

\footnotetext{
*Corresponding author: sjlee1225@hanmail.net
}

$11.3 \%$ of the total global fish catch, or $10,719,000$ $\mathrm{M} / \mathrm{T}$, in 2000 , comprising a large share of the fishery industry (FAO, 2000). In Korean waters, the South Sea is a major fishing ground for small pelagic fishes, and the population size shows a steady increase over time (NFRDI, 1998; Kim et al., 1999; Park et al., 2000; Zhang et al., 2004).

Small pelagic fishes tend to aggregate near the sea surface and are influenced by climate changes (Kim, 2003; Zhang et al., 2004). These ecological characteristics of small pelagic fishes lead to the expectation that recent global warming may affect population sizes and distributions. Thus, studies on the implications of long-term environmental changes including climate change on the population size of small pelagic fishes inhabiting the South Sea of Korea are imperative.

In this study, we investigated variation in the catch of small pelagic fishes, for which a major fishing ground exists in the South Sea of Korea, using long- 
term data. We also examined the relationship between long-term climatic changes and variation in the catch of small pelagic fishes.

\section{Materials and Methods \\ Weather conditions}

The variation in weather conditions in the southern part of the Korean peninsula was examined using long-term time-series data for air temperature, precipitation, wind speed, and relative humidity from four regions: Mokpo, Yeosu, Busan, and Jeju (Fig. 1). These data were collected over 33 years, from 19712003, by the Korea Meteorological Administration (KMA). For each meteorological factor, anomalies from the normal year mean represent the difference between the regional monthly actual value and a normal year mean value of the regional monthly mean for the KMA data from 1971-2000.

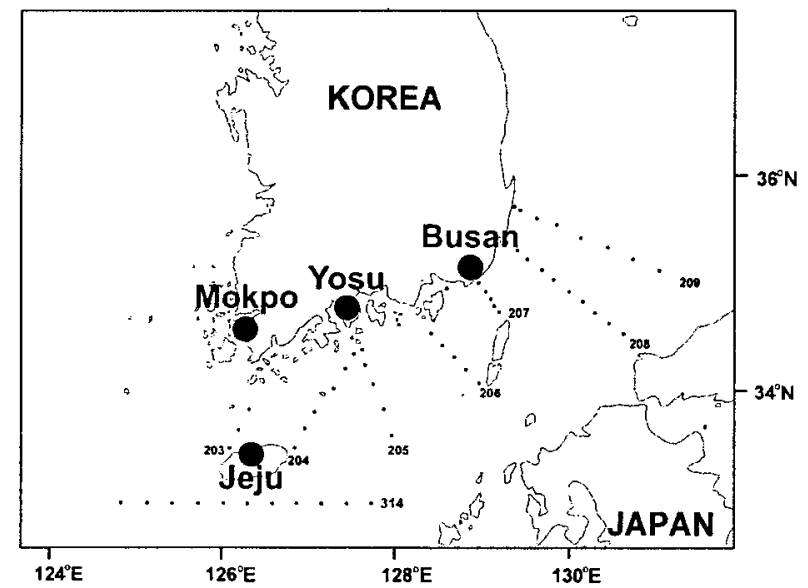

Fig. 1. Map showing the meteorological data observation areas (black circle) by KMA (Korea Meteorological Administration) and SST observation stations (dotted points) by NFRDI (National Fisheries Research \& Development Institute) in the South Sea of Korea from 1971 to 2003.

\section{Climate index}

The Southern Oscillation Index (SOI), i.e., the difference of the sea level pressure anomaly between Tahiti and Darwin, was downloaded from the homepage of the 'Southern Oscillation Index' provided by the Bureau of Meteorology Australia (http://www. bom.gov.au/climate/current/soi2.shtml). The North Pacific Index (NPI), the area-weighed sea level pressure over the region $30 \mathrm{~N}-65 \mathrm{~N}$ and $160 \mathrm{E}-140 \mathrm{~W}$, was downloaded from the homepage of 'An informed guide to climate data sets' provided by Adam Phillips, National Center for Atmospheric Research (http:// www.cgd.ucar.edu/cas/jhurrell/npindex.html).

\section{Oceanic conditions}

Variation in long-term oceanic conditions of the South Sea was examined using bimonthly observational sea surface temperature (SST) data at 53 stations along eight observational lines (Lines 203, 204, 205, 206, 207, 208, 209, and 314; Fig. 1). These data were collected over 33 years (1971-2003) by the National Fisheries Research \& Development Institute (NFRDI). The SST anomaly from a normal year mean represented the difference between the monthly actual value at each station and the normal year mean value at each point, from 1966-1995, taken from data of sea conditions in Korean waters (NFRDI, 1997).

\section{Catch data on major small pelagic fishes}

Published catch data for anchovy, common mackerel, and horse mackerel, for which a major fishing ground exists in the South Sea (NFRDI, 1998), were obtained from the Korean Ministry of Maritime Affairs and Fisheries (MOMAF). Yearly and monthly catch data from 1971-2003 for four regions in the southern part of the Korean peninsula, i.e., Jeollannam-do, Gyeongsangnam-do, Busan, and Jeju, were used in this study.

\section{Seasonal classification}

The seasonal classification of small pelagic fish catches and environmental factors was as follows: spring, from March to May; summer, June to August; autumn, September to November; and winter, December to February. Mean values were used in this study. For SST, which was observed every other month, winter values were represented by the means of data from February and December.

\section{Statistical analysis}

Correlation analysis and stepwise multiple regression were performed to examine the relationship between the catch of small pelagic fishes and environmental factors in the South Sea in winter. Owing to differences in the units of measurement, all data were standardized prior to analysis using the formula $(X i-X) / \mathrm{SD}$, where $X i$ represents observational data for variable $i$, and $X$ and SD are the mean and standard deviation, respectively (Johnson and Wichern, 1988).

\section{Results}

Annual changes in winter environmental factor anomalies

The long-term variation in winter weather factor 
anomalies, such as air temperature, precipitation, wind speed, and relative humidity pressure, in the southern part of the Korean peninsula, as well as the winter SST anomaly in the South Sea and winter climatic indices such as SOI and NPI are shown in Fig. 2. The air temperature anomaly ranged from -2.0 (1984) to $1.7^{\circ} \mathrm{C}(1998)$. Temperatures for most years until the mid-1980s were lower than that of an average year by $0.5-2.0^{\circ} \mathrm{C}$; after this time, the temperature began to increase. Air temperatures were consistently higher than average after the late 1980s. Variation in precipitation anomalies ranged from -22.3 (1977) to $42.6 \mathrm{~mm}$ (1989). Precipitation did not show a particular tendency and was often similar to normal years with some exceptions, such as 1989. Variation in the wind speed anomaly ranged from -0.5 (1992) to $0.7 \mathrm{~m} / \mathrm{s}(1971)$. Until the late $1980 \mathrm{~s}$, wind speed was similar to or greater than that of an average year. However, after the 1990s, wind speed was consistently lower, and the winter wind speed tended to decrease steadily. Variation in winter relative humidity anomalies ranged from $-7.2(2000)$ to $10.0 \%$ (1972). Until the early 1990 s, relative humidity was similar to or greater than that of an average year. After the early 1990 s, relative humidity was consistently lower. Variation in winter SST anomalies ranged from $-0.8(1975)$ to $1.3^{\circ} \mathrm{C}(1994)$. From the late 1980 s to 2003 , SST was consistently higher than average by $0.5-1.0^{\circ} \mathrm{C}$. The SST anomalies showed a pattern of variation similar to that of the air temperature anomalies. For the whole period, SOI and NPI changed irregularly, but the patterns of both showed similar trends in their fluctuations. Thus, winter in the southern part of the Korean peninsula gradually became warmer in the 1990 s, as did SST in the South Sea.

\section{Horizontal distribution of the winter SST anomaly in the South Sea}

The horizontal distribution of winter SST anoma-
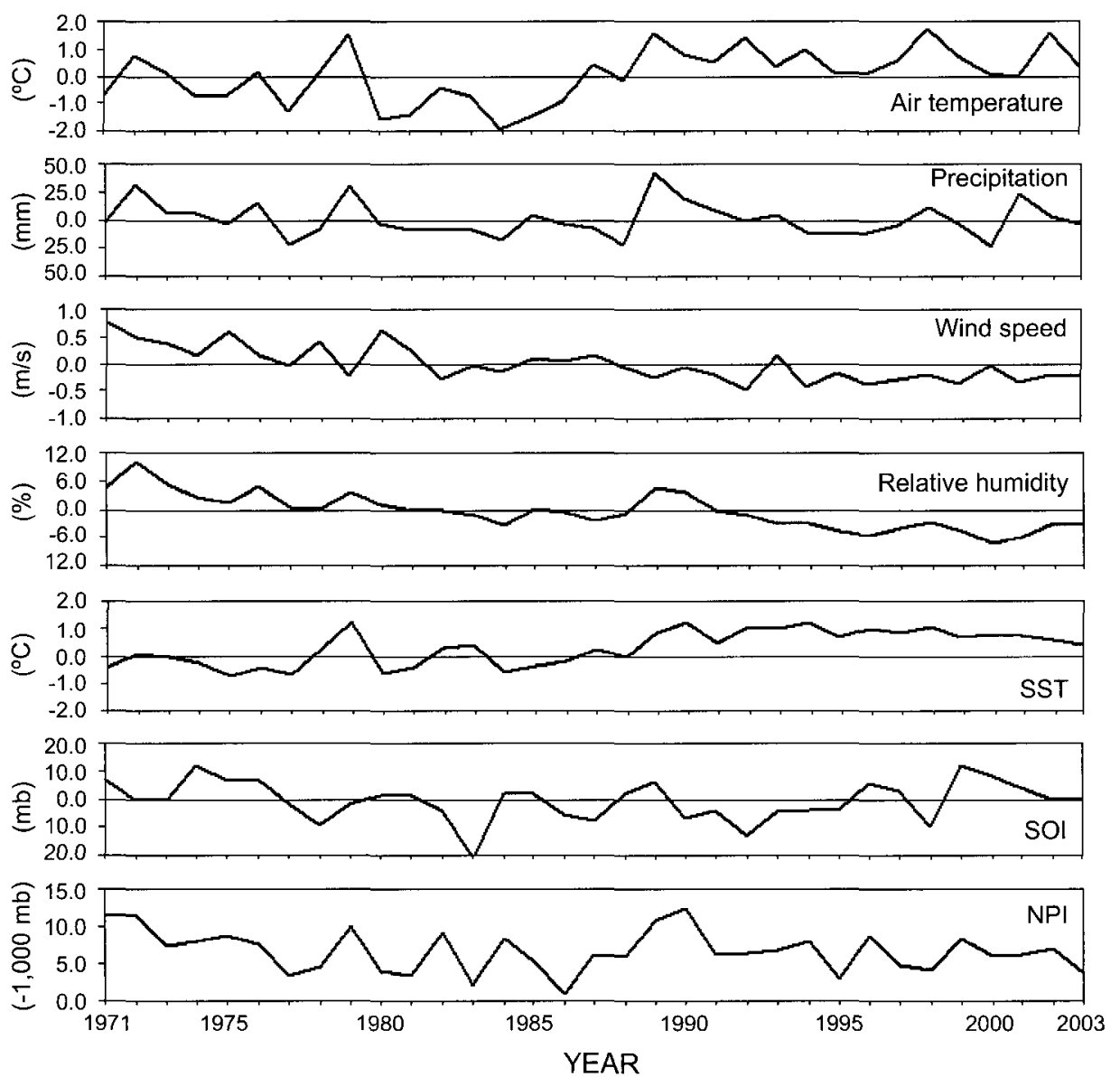

Fig. 2. Annual changes of winter meteorological factor anomalies in the southern part of Korean peninsula and winter SOI anomaly with NPI value, and winter SST anomaly in the South Sea of Korea from 1971 to 2003. 


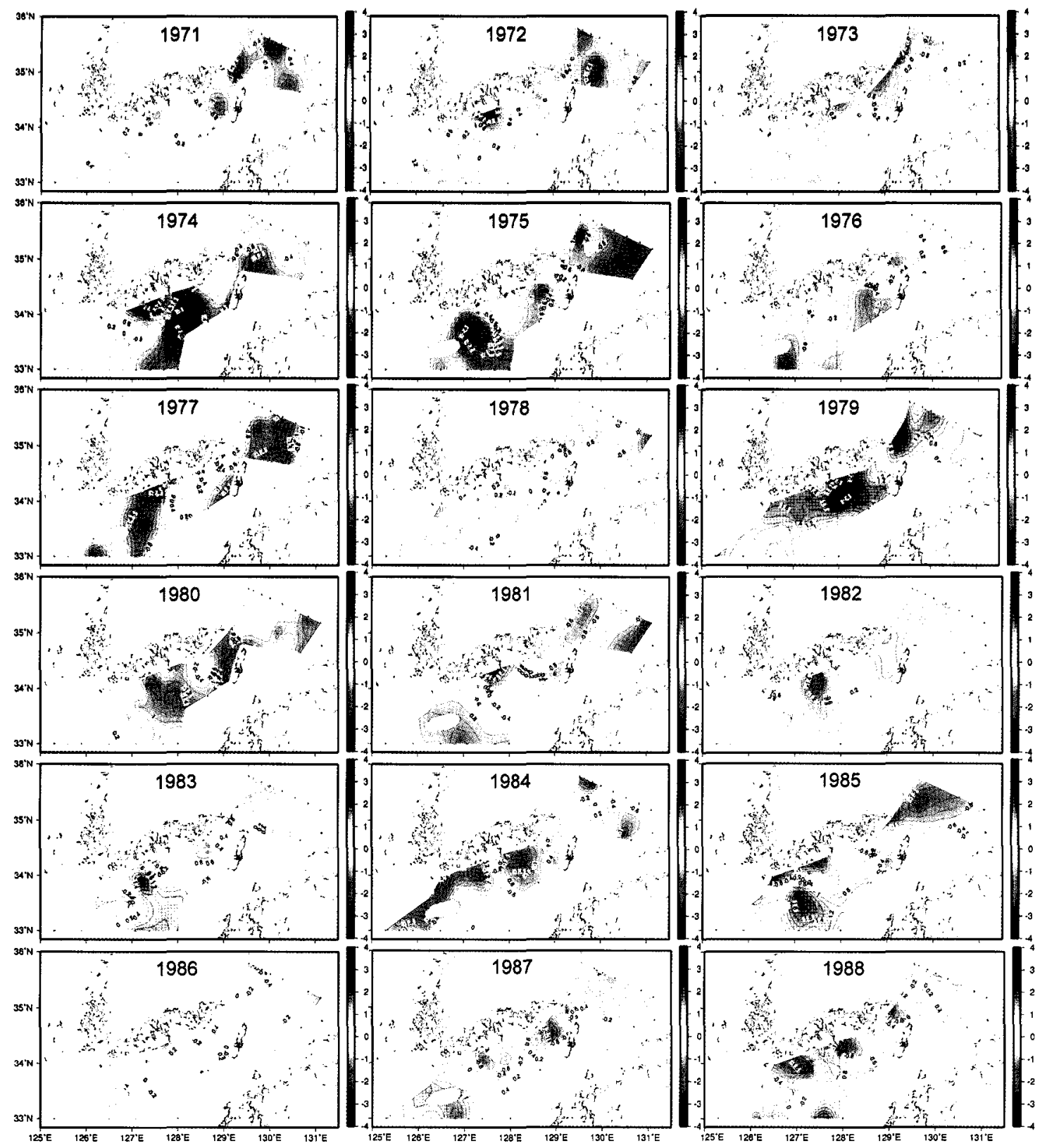

Fig. 3. Annual variation in horizontal distribution of SST anomalies in winter (February and December) in the South Sea of Korea from 1971 to 2003.

lies in the South Sea over time is shown in Fig. 3. In the $1970 \mathrm{~s}$, SST anomalies ranged from -3.0 to $2.9^{\circ} \mathrm{C}$ throughout the whole South Sea, and in most areas, SST was similar to or lower than that of an average year. A cold water zone, with a temperature $2-3^{\circ} \mathrm{C}$ lower than average, formed in the middle and western parts of the South Sea in 1974 and 1975, respectively. In the $1980 \mathrm{~s}$, SST anomalies ranged from -2.6 to $3.8^{\circ} \mathrm{C}$. Water masses that were lower in temperature than average by $1-2^{\circ} \mathrm{C}$ were found in the middle of the South Sea and northwest of Jeju Island in 1980 and 1984, respectively. In contrast, in 1989, a water mass with higher temperatures than average by $1-2^{\circ} \mathrm{C}$ was found east of Jeju Island. From the 1990s on, SST anomalies ranged from -2.1 to $2.5^{\circ} \mathrm{C}$. Except for cold water zones that were lower in temperature than average by $2^{\circ} \mathrm{C}$ that formed in 1999 and 2003 , water masses with temperatures $1-2^{\circ} \mathrm{C}$ higher than average were widely distributed in most areas, unlike in the 1970s and 1980s. Examination of winter oceanic con- 


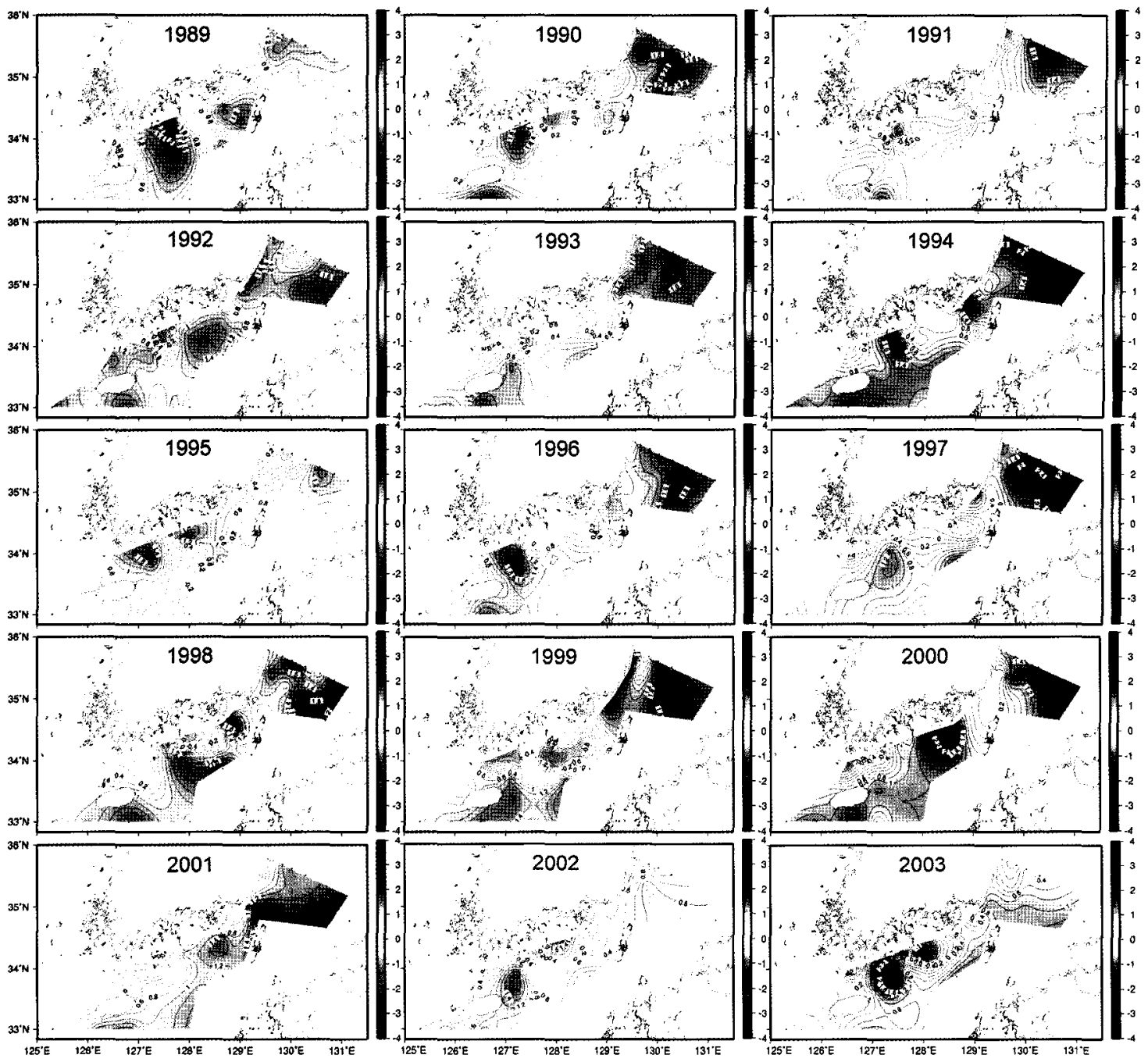

Fig. 3. Continued.

ditions in the South Sea over time showed that hightemperature water masses appeared primarily in the 1990s.

\section{Annual changes in the small pelagic fish catch}

The annual variation in the catch of total fishes and major small pelagic fishes in the South Sea from 1971-2003 are shown in Fig. 4. The mean catch of total fishes in the South Sea over the 33 years was $990,198 \mathrm{M} / \mathrm{T}$. In 1971, the annual catch was 573,608 $\mathrm{M} / \mathrm{T}$; this increased steadily during the mid-1980s and reached $1,378,018 \mathrm{M} / \mathrm{T}$ in 1986 . However, a large decrease in the annual catch began in the late 1980s, with only $714,058 \mathrm{M} / \mathrm{T}$ caught in 2002 . On the other hand, the major small pelagic fish catch began to increase again and reached a maximum of 651,054 $\mathrm{M} / \mathrm{T}$ in 1996. In particular, the proportion of major small pelagic fishes accounted for at least $30.6 \%$ of the total fish catch in the South Sea during the period of investigation.

\section{Seasonal variation in the major small pelagic fish catch in the South Sea}

The variation in the 3-year moving averages of the small pelagic fish catch and the catch proportion from the South Sea by season from 1971-2003 are shown in Fig. 5 and Fig. 6, respectively. During the period examined, the mean winter catch was $70,579 \mathrm{M} / \mathrm{T}$.

The winter catch was as low as $50,000 \mathrm{M} / \mathrm{T}$ until the mid-1980s; it showed a rapid increase from the late $1980 \mathrm{~s}$, and was high, over $120,000 \mathrm{M} / \mathrm{T}$, after the late 1990s. Summer and autumn catches showed similar trends, with mean catches of $82,393 \mathrm{M} / \mathrm{T}$ and $90,217 \mathrm{M} / \mathrm{T}$, respectively. Both summer and autumn 


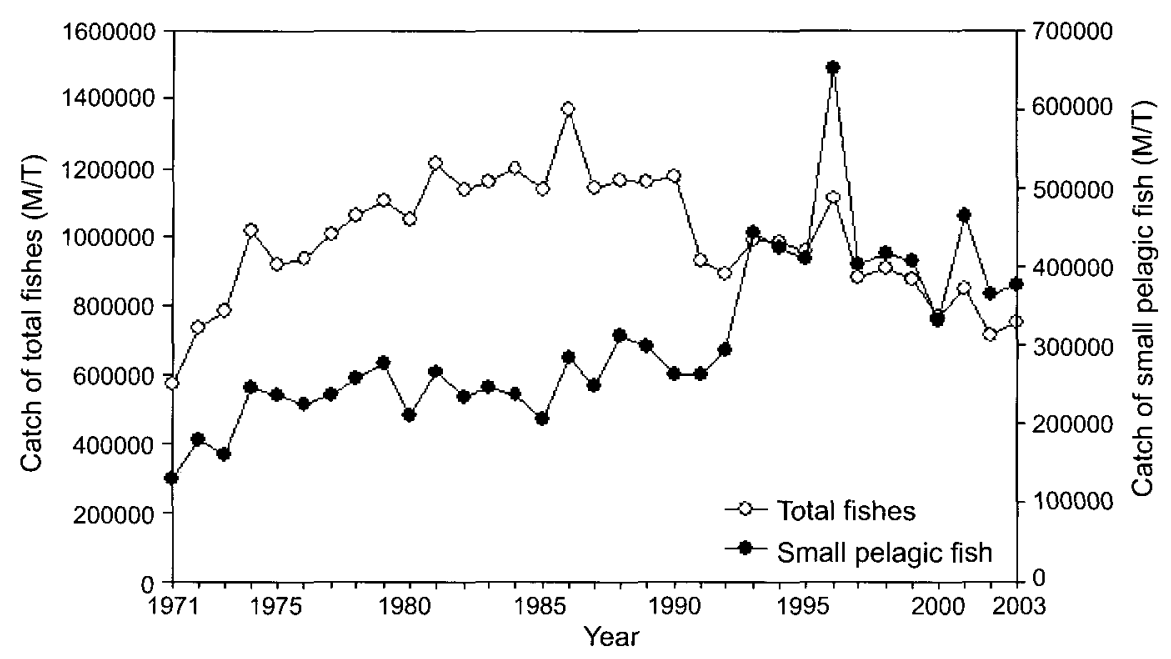

Fig. 4. Fluctuations in annual catch of total fishes and major small pelagic fishes (anchovy, common mackerel and horse mackerel) in the South Sea of Korea from 1971 to 2003.

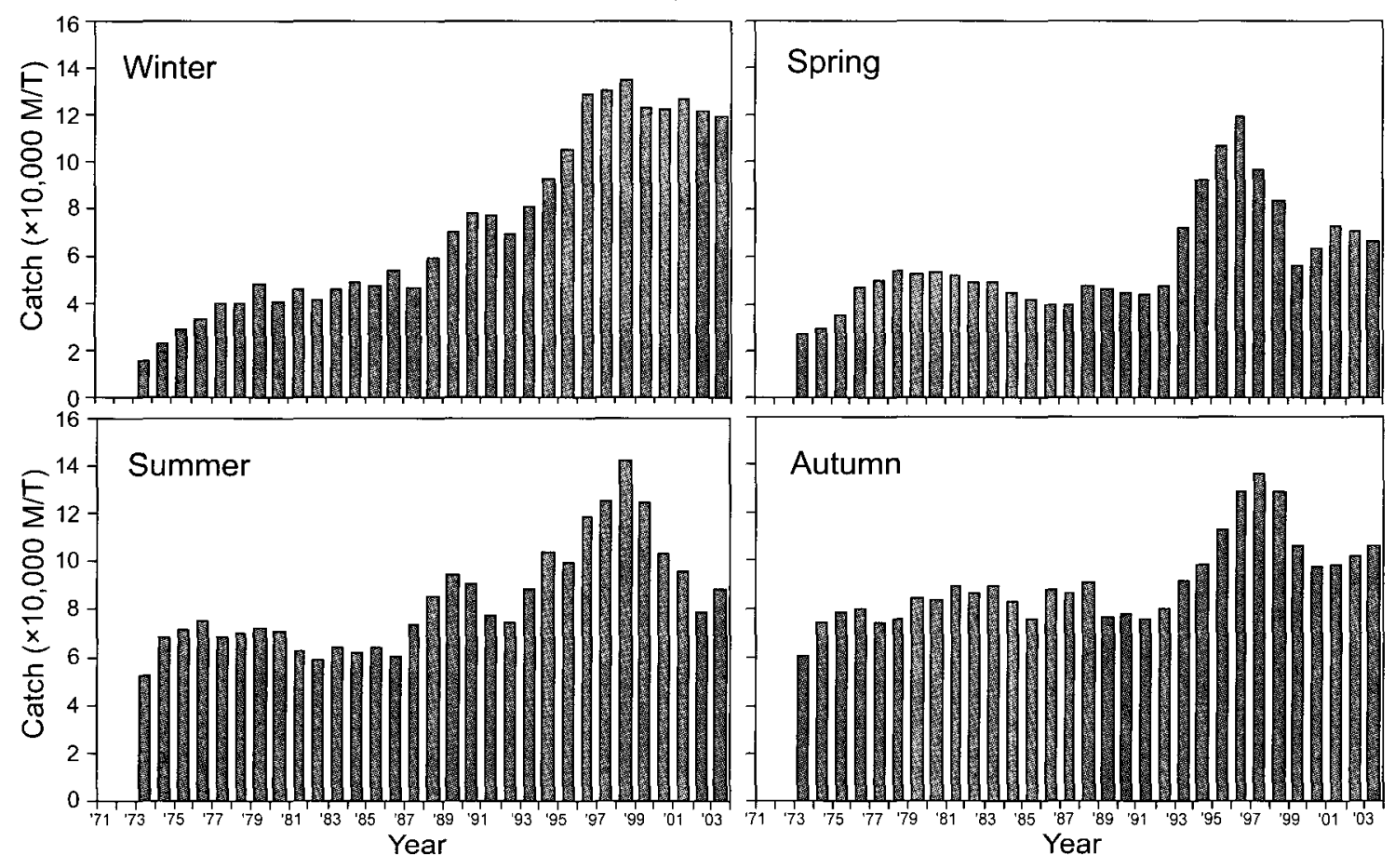

Fig. 5. Seasonal variations in the three-year moving averages catch of major small pelagic fishes in the South Sea of Korea from 1971 to 2003.

catches maintained low levels around $80,000 \mathrm{M} / \mathrm{T}$ until the early 1990s; they increased to about 100,000 $\mathrm{M} / \mathrm{T}$ in the mid-1990s. Since the late 1990s, however, both summer and autumn catches have tended to decrease. Among the seasons, the mean spring catch was the lowest, at $56,913 \mathrm{M} / \mathrm{T}$. The spring catch remained at around $60,000 \mathrm{M} / \mathrm{T}$ until the early 1990s; it increased slightly in the mid-1990s. After the late 1990s, however, the spring catch decreased steadily. The proportion of small pelagic fishes harvested from the South Sea differed between winter and the other seasons, for which the catch decreased over time (Fig. 6). The winter proportion of small pelagic fishes taken from the South Sea increased steadily from $15.0 \%$ in the $1970 \mathrm{~s}$, to $26.8 \%$ in the $1990 \mathrm{~s}$, and to as much as $32.9 \%$ in the early $2000 \mathrm{~s}$. 


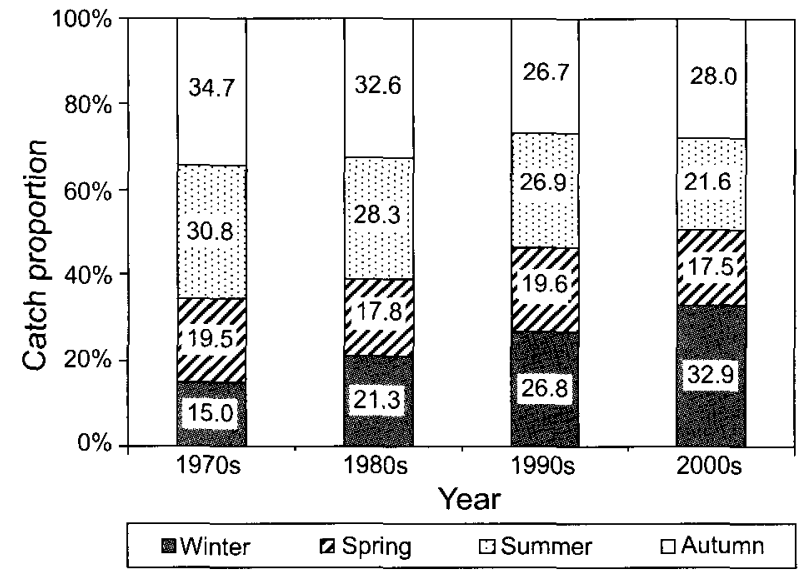

Fig. 6. Seasonal variations in catch proportion of major small pelagic fishes in the South Sea of Korea from 1971 to 2003 .

\section{Correlations between the winter catch of major small pelagic fishes and environmental factors}

The correlation coefficients between the major small pelagic fish catch and environmental factor anomalies during winter are shown in Table 1 . The major small pelagic fish catch $(Y)$ was positively related to air temperature $\left(X_{1}, r=0.468, P<0.01\right)$ and SST $\left(X_{5}\right.$, $r=0.672, \quad P<0.01)$. On the other hand, $Y$ was negatively related to wind speed $\left(X_{3}, r=-0.732\right.$, $P<0.01)$ and relative humidity $\left(X_{4}, r=-0.731, P<\right.$ $0.01)$. Air temperature $\left(X_{1}\right)$ in the southern part of the Korean peninsula showed a significant correlation with precipitation $\left(X_{2}, r=0.498, P<0.01\right)$ and wind speed $\left(X_{3}, r=-0.465, P<0.01\right)$, and a high significant correlation with SST $(r=0.800, P<0.01)$ in the South Sea, particularly during winter. Wind speed $\left(X_{3}\right)$ showed a significant correlation with relative humidity $\left(X_{4}, r=0.553, P<0.01\right)$ and SST $\left(X_{5}, r=-0.677\right.$, $P<0.01)$. NPI $\left(X_{7}\right)$ was significantly correlated with precipitation $\left(X_{2}, r=0.476, P<0.01\right)$, relative humidity $\left(X_{4}, r=0.464, P<0.01\right)$, and SOI $\left(X_{6}, r=0.38\right.$, $P<0.05)$.

\section{Multiple regression analysis}

The results of stepwise multiple regression with winter small pelagic fish catches from the South Sea over 33 years (1971-2003) as the dependent variable $(Y)$ and winter environmental factors as independent variables $(X)$ are shown in Table 2 . The following formula was obtained; $Y=-0.017-0.217 X_{3}-0.486$ $X_{4}+0.325 X_{5}\left(R^{2}=0.754, P<0.000\right)$.

To improve the multiple regression analysis results, the factor of air temperature, which had a high correlation coefficient with SST (Table 1), was excluded. Based on the multiple regression equation, there were three major variables affecting the winter small pelagic fish catch. The partial regression coefficients of wind speed, relative humidity, and SST were $-0.217,-0.468$, and 0.325 , respectively, which implies that decreasing wind speed and relative humidity and increasing SST were major factors affecting in particular the increases in winter small pelagic fish catches. In addition, the coefficient of multiple determination $R^{2}$ was 0.754 , and appro-

Table 1. Correlation coefficients between the winter catch of small pelagic fishes $(Y)$ and winter environmental variables $(X)$ during the survey period

\begin{tabular}{|c|c|c|c|c|c|c|c|}
\hline & $\gamma$ & $X_{1}$ & $x_{2}$ & $x_{3}$ & $X_{4}$ & $x_{5}$ & $x_{6}$ \\
\hline$X_{1}$ & $+0.468^{* *}$ & & & & & & \\
\hline$x_{2}$ & -0.088 & $+0.498 * *$ & & & & & \\
\hline$x_{3}$ & $-0.732 * *$ & $-0.465^{* * *}$ & +0.004 & & & & \\
\hline$x_{4}$ & $-0.731^{* *}$ & +0.000 & $+0.572^{* *}$ & $+0.553^{* *}$ & & & \\
\hline$x_{5}$ & $+0.672 * *$ & $+0.800 * *$ & +0.277 & $-0.677^{* *}$ & $-0.353^{*}$ & & \\
\hline$x_{6}$ & +0.088 & -0.156 & +0.070 & +0.142 & +0.051 & -0.288 & \\
\hline$x_{7}$ & -0.116 & +0.322 & $+0.476 * *$ & +0.066 & $+0.464 * *$ & +0.181 & $+0.387^{*}$ \\
\hline
\end{tabular}

$Y$, catch of small pelagic fish; $X_{1}$, anomaly of air temperature; $X_{2}$, anomaly of precipitation; $X_{3}$, anomaly of wind speed; $X_{4}$, anomaly of relative humidity; $X_{5}$, anomaly of SST; $X_{6}$, anomaly of SOI; $X_{7}$, anomaly of NPI. *, significant at $5 \%$ level; **, significant at $1 \%$ level

Table 2. Result in stepwise multiple regression analysis to determine the variables $(X)$ effects on the catch of small pelagic fishes $(Y)$ in winter

\begin{tabular}{ccccccccc}
\hline \multirow{2}{*}{ Steps } & $a_{0}$ & $X_{3}$ & $X_{4}$ & $X_{5}$ & \multirow{2}{*}{$R^{2}$} & & F & P-ratio \\
\cline { 2 - 5 } & & $b_{1}$ & $b_{2}$ & $b_{3}$ & & & & \\
\hline 1 & -0.021 & -0.681 & & & & 0.536 & 35.772 & 0.000 \\
2 & -0.012 & -0.440 & -0.475 & & 0.689 & 33.294 & 0.000 \\
3 & -0.017 & -0.217 & -0.486 & +0.325 & 0.754 & 29.549 & 0.000 \\
\hline
\end{tabular}

$X_{3}$, wind speed; $X_{4}$, relative humidity; $X_{5}$, SST. 


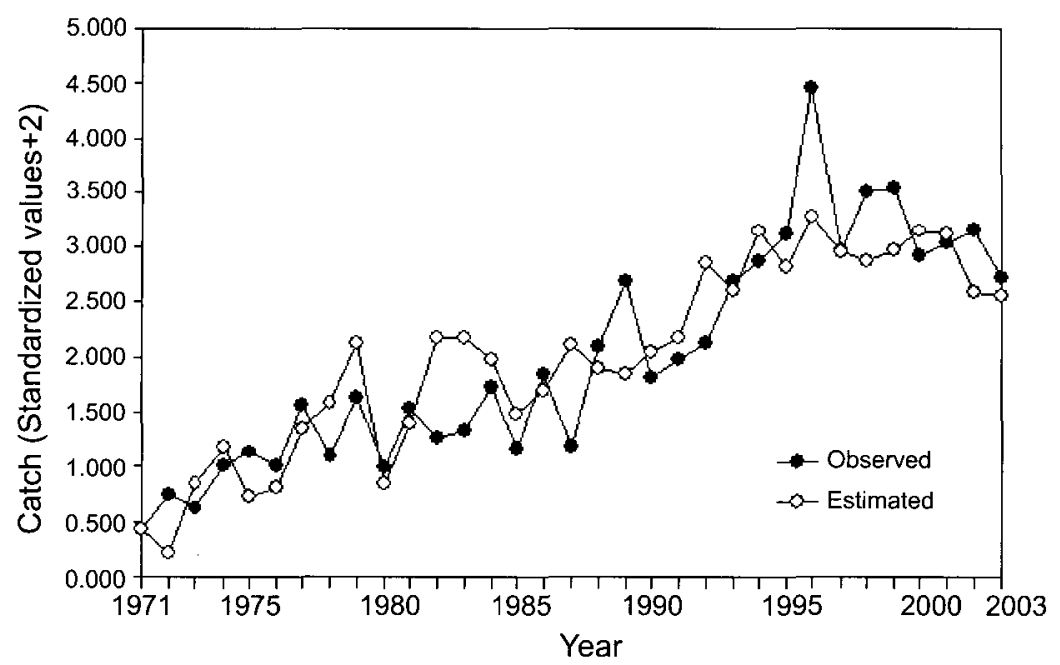

Fig. 7. Comparison between observed values and estimated values for the winter small pelagic fishes catch in the South Sea of Korea by the final regression equation shown in Table 2.

ximately $75 \%$ of the variation in the catch of small pelagic fishes was explained by these data.

Fig. 7 shows the estimated values for the winter small pelagic fish catches in the South Sea by the final multiple regression equation with observed values. Variation in the estimated and observed small pelagic fish catches showed similar patterns. Although in each period there were exceptional years, the range of the fluctuation in the estimated values was similar to or higher than the observed values.

\section{Discussion}

Recently, global climate has changed rapidly, given increasing greenhouse gases and abnormal climate conditions such as El Niño. According to the Intergovernmental Panel on Climate Change (IPCC), global warming is accelerating; the average air temperature has increased about $0.6^{\circ} \mathrm{C}$ since 1860 (IPCC, 2001). The Korean peninsula, which is located in the northwest Pacific Ocean, is no exception. It has experienced an increase in average annual air temperature of $1.5^{\circ} \mathrm{C}$ in the $20^{\text {th }}$ century, as well as other climate changes, including an increase in heavy rainfall events, over the past two decades. In particular, the rate of air temperature warming in the Korean peninsula has exceeded that of other areas since the 1990s (Choi et al., 2003; Kwon et al., 2003).

In this study, major meteorological changes in the southern part of the Korean peninsula for the winter season over the period from 1971 to 2003 were clear. First, the mean air temperature in winter showed a steady increase from $4.3^{\circ} \mathrm{C}$ in the $1970 \mathrm{~s}$ to $4.8^{\circ} \mathrm{C}$ after 2000. The mean wind speed in winter, the other hand, weakened from $4.8 \mathrm{~m} / \mathrm{s}$ to $4.4 \mathrm{~m} / \mathrm{s}$ over the same time period. The mean relative humidity in winter also decreased from $66.3 \%$ in the 1970 s to $57.8 \%$ after 2000. These figures indicate that the southern part of the Korean peninsula in winter has been under the influence of global warming with a decrease in relative humidity, weakened seasonal winds, and an increase in air temperature since the 1990s.

With regard to the atmospheric conditions discussed above, various studies have reported a marked change in the winter temperature of the seas surrounding South Korea (Kang, 2000; Park and Oh, 2000). In this study, the long-term changes in SST of the southern area of Korea during winter revealed that the mean SST increased to $15.3^{\circ} \mathrm{C}$ after 2000 from $14.8^{\circ} \mathrm{C}$ in the $1970 \mathrm{~s}$. Also, the deviation of winter air temperature changed at a rate very similar to that of SST ( $r=0.800, P<0.01$, Table 1), implying a strong correlation between air and sea temperatures. Consequently, these results suggest that the weather changes in the southern part of the Korean peninsula in winter are closely related to oceanic conditions in the South Sea of Korea. In other words, it can be concluded that the increase in SST of the South Sea during winter was mainly caused by continuous dryness, resulting from a decrease in relative humidity, a decline in seasonal wind strength, and an increase in winter air temperature, in the southern part of the Korean peninsula since the 1990s.

Small pelagic fishes, which generally cluster near the ocean surface, live for a relatively short period of time and grow rapidly to a length at which they can be caught (Kawasiki, 1993; Watanabe et al., 1995). This characteristic makes them susceptible to various environmental factors in terms of their recruitment 
and adult populations. In Korean waters, the variation in catches in commercial fisheries such as squid, walleye pollock, anchovy, mackerel, and jack mackerel was caused by climatic changes such as warming in the late 1980s and early 1990s around the Korean peninsula (Kang and Kim, 2002; Kim and Kang, 2000; Kang et al. 2002; Zhang et al., 2000).

In the results for the catch proportion of small pelagic fishes in the South Sea of Korea by time period and season, the winter catch proportion showed a distinct trend. While the catch proportion in other seasons remained constant or decreased, that in winter increased from $15.0 \%$ in the 1970 s, to $26.8 \%$ in the $1990 \mathrm{~s}$, to $32.9 \%$ after 2000 . In this regard, we presume that climate warming in the southern area caused the increased catch of small pelagic fishes in winter. Two possibilities can be considered. First, the increased SST since the 1990s may have led to more food organisms for small pelagic fishes in the South Sea of Korea. According to Kim and Kang (2000), higher water temperatures resulting from climate warming have caused a sharp increase in the biomass of zooplankton in most of the Korean coastal areas since the late 1980 s or the early 1990 s. In a related study, Kang et al. (2002) suggested that the rapid increase in biomass of zooplankton in winter may be attributable to the warmer winter in the Japan/East Sea since the late 1980s. Therefore, it is suggested that environmental changes such as increasing SST have led to signifycant changes in the oceanic ecosystem, including higher trophic levels as well as primary producers. It is assumed that climate warming in the southern part of the Korean peninsula in the early 1990s caused increases in SST and in the biomass of zooplankton, which is a major food organism for small pelagic fishes, ultimately leading to increased small pelagic fish populations.

The other possibility is that a higher SST in the South Sea in winter may have expanded the habitat and movement range of small pelagic fishes. Park et al. (2000) reported that in recent years, migratory fishes including common mackerel, horse mackerel, anchovy, and yellow tail were observed in a wider region of the South Sea in winter, expanding their habitat to the north. In addition, as the ocean temperature became warmer between 1981 and 1991, the common squid, which, like small pelagic fishes, has a short life span and is highly susceptible to oceanic environmental changes, began spawning in the Korea Strait and the seas around Koto Island, unlike in the past (Kiyofuji et al., 1998).

Through the analysis of horizontal distribution of SST anomalies in the South Sea, we found that warm water masses were widespread in the entire region in the 1990s. This may have affected the distribution of small pelagic fishes that feed and form fishing grounds mainly in the South Sea. Therefore, it is possible that the higher SST in winter in the South Sea area from the early 1990 s expanded the movement range of small pelagic fishes, which previously decreased in winter. Consequently, the size and forming time of fishing grounds increased. In conclusion, climate warming in the southern part of the Korean peninsula from the 1990 s, particularly in winter, has brought about changes in the physical and biological environments such as higher water temperature and more food for small pelagic fishes, which in turn has increased the population of small pelagic fishes.

Although it was hard to find direct relations between the global climate indices such as SOI and NPI and changes in the catch of small pelagic fishes, the regime shift occurring in the North Pacific area from the mid-1970s had a noticeable impact on primary production of the ocean. We also found a significant relation between NPI and other meteorological factors in the southern part of Korean peninsula, including precipitation $(r=0.476, P<0.01$, Table 1$)$ and relative humidity $(r=0.464, P<0.01$, Table 1$)$, and between SOI and NPI to a certain degree $(r=0.387$, $P<0.05$, Table 1 ). This suggests that global climate change is tele-connected to the climate system of Korea, and the ecosystem in the South Sea is responding to the change with a time lag. This demonstrates the need to clarify the relations between global and regional climate elements and to analyze how the ecosystem in the Korean coastal area has responded.

In this study, a correlation analysis and stepwise multiple regression analysis were used to identify factors influencing the winter catch of small pelagic fishes. The results showed that the increasing catches of small pelagic fishes were affected by meteorologycal factors such as weakening wind speed and increasing relative humidity, and by physical factors such as increasing SST (Table 2), suggesting that the population fluctuation of small pelagic fishes in the South Sea depends strongly on the changes in climatic conditions and SST. It is therefore considered that the climatic conditions and SST play an important role in population regulation of small pelagic fishes in the South Sea. For the more accurate information, we need further studies considering the ecological characteristics of the fish species during their spawning and nursery periods, and the changes in fishing fleets operating in the coastal area and their unit productivity since the 1970 s. 


\section{Acknowledgements}

This work was supported by a grant from the Bukjeju Marine Ranching Program, 2006 funded by MOMAF, Korea.

\section{References}

Choi, Y., K.Y. Nam, H.S. Jung and W.T. Kwon. 2003. Estimating and correcting urban bias in surface temperature time series of Korea. Inter. J. Climatol., 23, 577-591

FAO. 2000. FAO Yearbook of Fishery Statistics, 91, 189 191.

IPCC. 2001. Climate Change 2001: The Scientific Basis. Contribution of Working Group I to the Third Assessment Report of the Intergovernmental Panel on Climate Change. Houghton, J.T., Y. Ding, D.J. Griggs, N. Nogurer, P.J. van der Linden, X. Dai, K. Maskell and C.A. Johnson (Eds), Cambridge University Press, Cambridge, United Kingdom, 1-881.

Johnson, R.A. and D.W. Wichern. 1988. Applied Multivariate Statistical Analysis. Prentice Hall, London, pp. 594.

Kang, Y.Q. and S.A. Kim. 2002. Zooplankton in the Korean waters. In: D. Lee ed., Ecology of Korea. Bumwoo Publishing Co. Seoul, Korea, pp. 331-343.

Kang, Y.Q. 2000. Warming tend of coastal waters of Korea during Recent 60 Years (1936-1995). J. Fish. Sci. Technol., 3, 173-179.

Kang, Y.S., J.Y. Kim, H.G. Kim and J.H. Park. 2002. Long-term changes in zooplankton and its relationship with squid, Todarodes pacificus, catch in Japan/East Sea. Fish. Oceanogr., 11, 337-346.

Kawasaki, T. 1993. Recovery and collapse of the far eastern sardine. Fish. Oceanogr., 2, 244-253.

Kim, J.Y, Y.S. Kang and H.D. Jeong. 1999. Long-term variations in population biomass of mackerel, Scomber japonicus and environmental factors in Korean waters. J. Kor. Soc. Fish. Res., 2, 92-100.

Kim, S.A. and S.Y. Kang. 2000. Ecological variation and El Niño effects off the southern coast of the Korean Peninsula during the last three decades. Fish. Oceanogr., 9, 239-247.

Kim, S.A. 2003. Changes in fisheries resources in relation to variability of oceanic environments. J. Kor. Soc.
Fish. Res., 6, 11-20.

Kiyofuji, H., S. Saitoh and Y. Sakurai. 1998. A visualization of the variability of spawning ground distribution of Japanese common squid (Todarodes pacificus) using marine-GIS and satellite data sets. In: Proceedings of International Symposium Real-time Imaging and Dynamics Analysis. International Society of Photogrametry and Remote Sensing Commission V, $882-887$

Kwon, W.T., Y. Choi, J.H. Oh and H.J. Baek. 2003. Understanding of regional climate change in Korea. In: The First Symposium on Climate Change, Oceanography and Fisheries. Natl. Fish. Res. Dev. Inst. Busan, Korea, $17-20$.

Lee, C.L. 2004. Review of the Fish-fauna of the West Sea of Korea. Kor. J. Ichthyol., 16, 60-74.

NFRDI (National Fisheries Research and Development Institute). 1997. Climatic Atlas of T, S, DO in Korean Waters (1966-1995). Ye-Moon Publication Co. Busan, Korea, 1-268.

NFRDI (National Fisheries Research and Development Institute). 1998. Ecology and fishing grounds of major fish species in the Korean coastal and offshore area. Ye-Moon Publication Co. Busan, Korea, 1-304.

Park, J.H., K.S. Hwang and Y.S. Kang. 2000. Variation of fishing condition and the winter warming in Korean waters. J. Kor. Soc. Fish. Res., 3, 77-87.

Park, W.S. and I.S. Oh. 2000. Interannual and interdecadal variations of sea surface temperature in the east Asian marginal seas. Prog. Oceanogr., 47, 191-204.

Watanabe, Y., H. Zeromu and R. Kimura. 1995. Population decline of the Japanese sardine, Sardinops melanostictus, owing to recruitment failures. Can. J. Fish. Aquat. Sci., 52, 1609-1616.

Zhang, C.I., J.B. Lee, S.A. Kim and J.H. Oh. 2000. Climatic regime shifts and their impacts on marine ecosystem and fisheries resources in Korean waters. Prog. Oceanogr., 47, 171-190.

Zhang, C.I., J.B. Lee, Y.I. Seo, S.C. Yoon and S.A. Kim. 2004. Variations in the abundance of fisheries resources and ecosystem structure in the Japan/East Sea. Prog. Oceanogr., 61, 245-265.

(Received October 2006, Accepted March 2007) 